\title{
Isolation and Characterization of Cryptococcus neoformans Urease Complex
}

Noor Fatin Omar ${ }^{1}$, Shun Iwatani ${ }^{1}$, Akio Toh-E ${ }^{2}$, Susumu Kajiwara ${ }^{1}$

${ }^{1}$ Life Science and Technology, Tokyo Institute of Technology, Yokohama City, Kanagawa 226-8503, Japan

${ }^{2}$ Medical Mycology Research Center, Chiba University, Chiba City, Chiba 260-8673, Japan

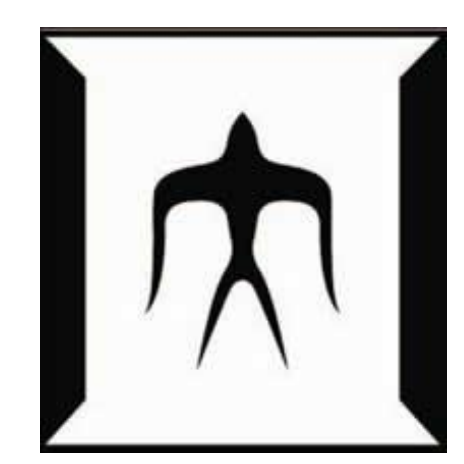

Introduction: Urease activity of Cryptococcus neoformans had been shown to be involved in cryptococcal cells transmigration across human blood brain barrier (BBB). Activation of urease apoenzyme requires accessory proteins, which are Ure4, Ure6 and Ure7 which will form a complex to incorporate nickel cofactor to its active site. To characterize this enzyme and to understand its mechanism, we try to obtain biologically active urease enzyme by tagging one of the urease complex subunits with 3XFLAG tag to assist in urease complex purification by affinity chromatography.

Beside that, urease activity was abolished when $\mathrm{VPH} 1$ gene, an isoform of subunit 'a' of $\mathrm{V}_{0}$ portion of V-ATPase was disrupted, triggering curiosity to study this phenomenon deeply. $\Delta v p h 1$ cells was used to study its correlation to urease complex formation and urease activity coordination.

\section{Results:}

(a) C-terminal
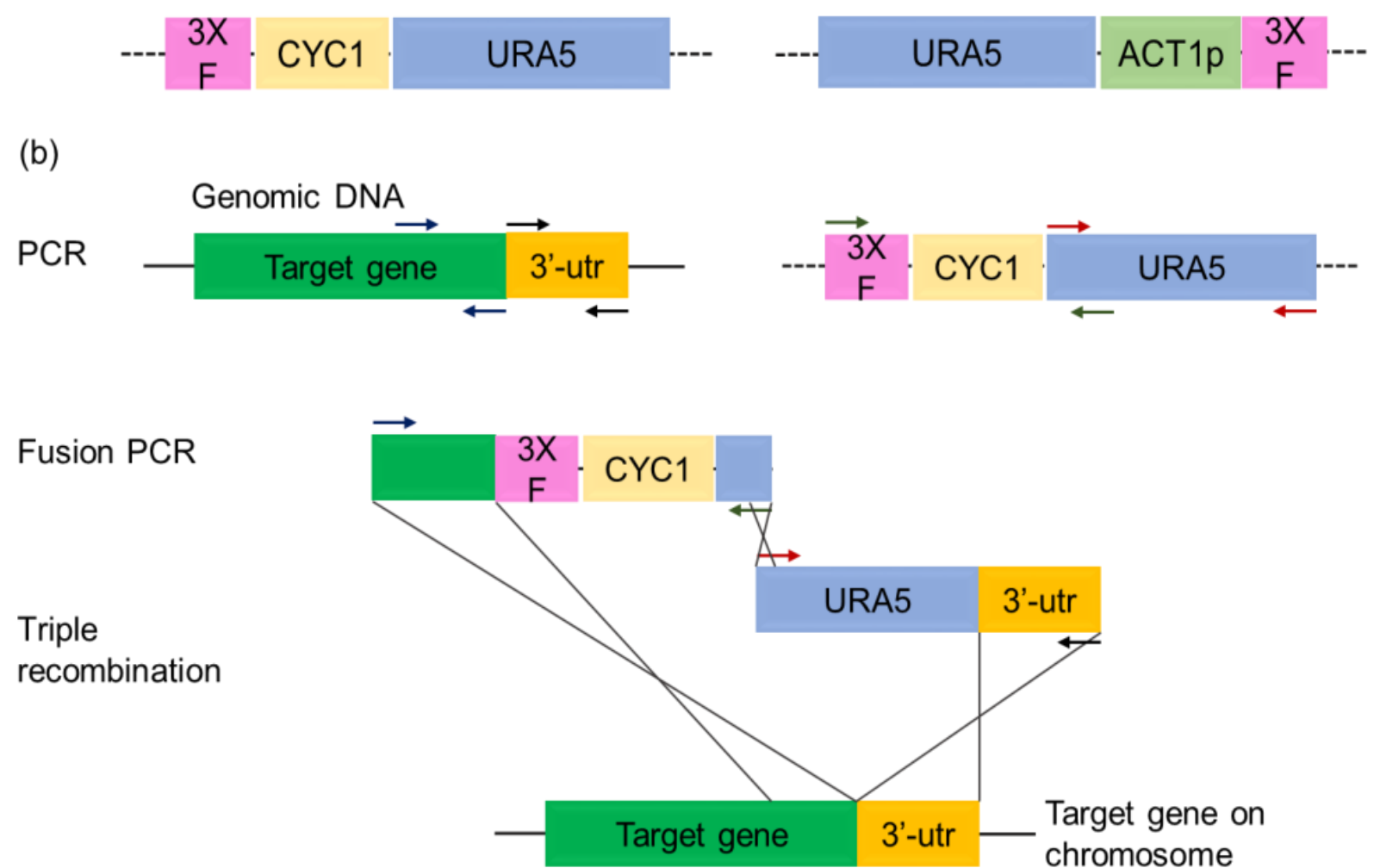

Fig. 1: A urease complex subunit was fused with 3XFLAG tag by homologous recombination. (a) 3XFLAG fusion tag for $\mathrm{C}$ - and $\mathrm{N}$ terminal tagging. (b) For simplicity, the figure depicts the production of C-terminal tag.

(a)
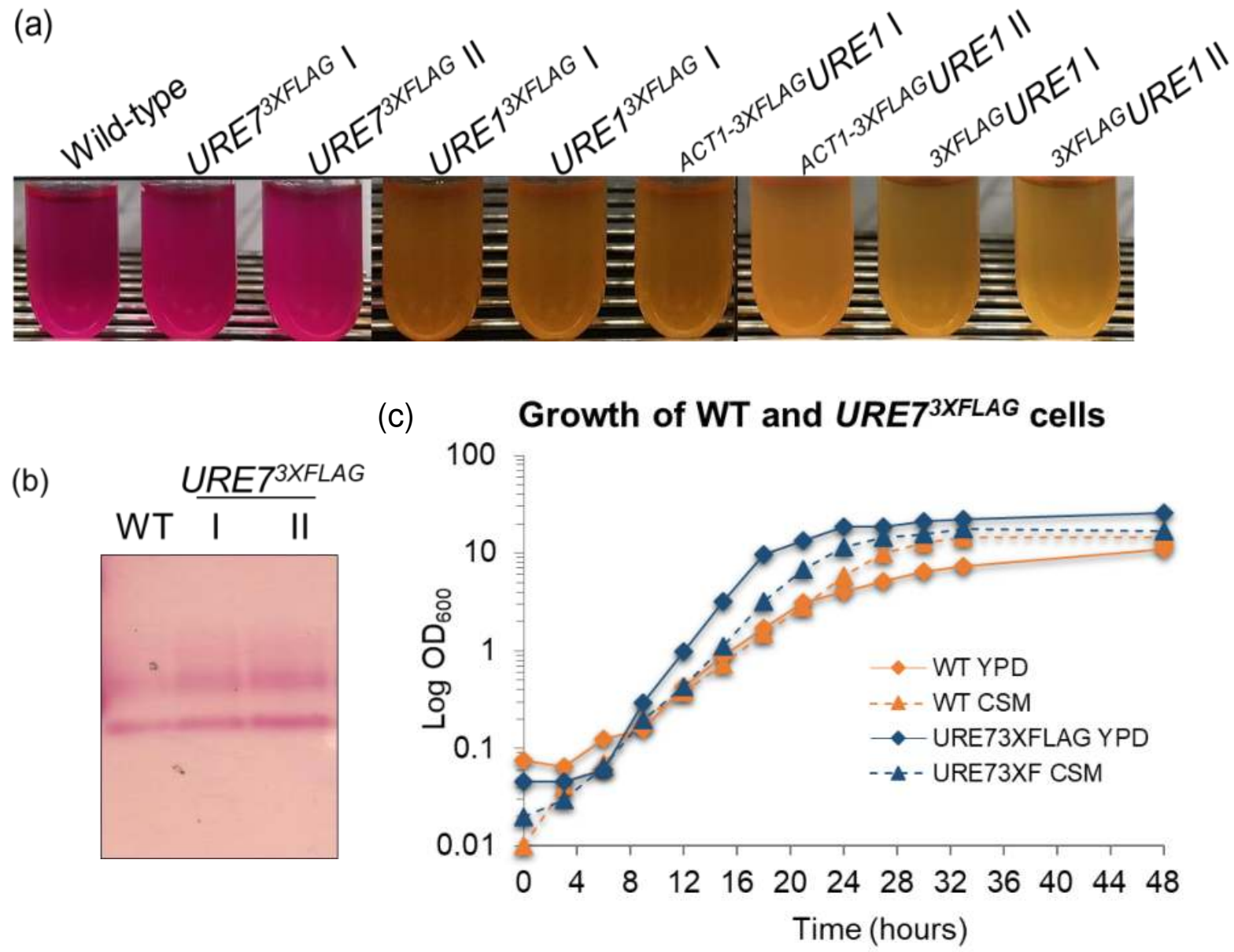

Fig. 2: URE73XFLAG modified strain able to retain urease activity and able to grow well. (a) Growth of $C$. neoformans cells in Stuart's urea broth for two days at $30^{\circ} \mathrm{C}$, (b) In gel detection of urease activity, (c) Growth in YPD and CSM with $0.227 \%$ urea.
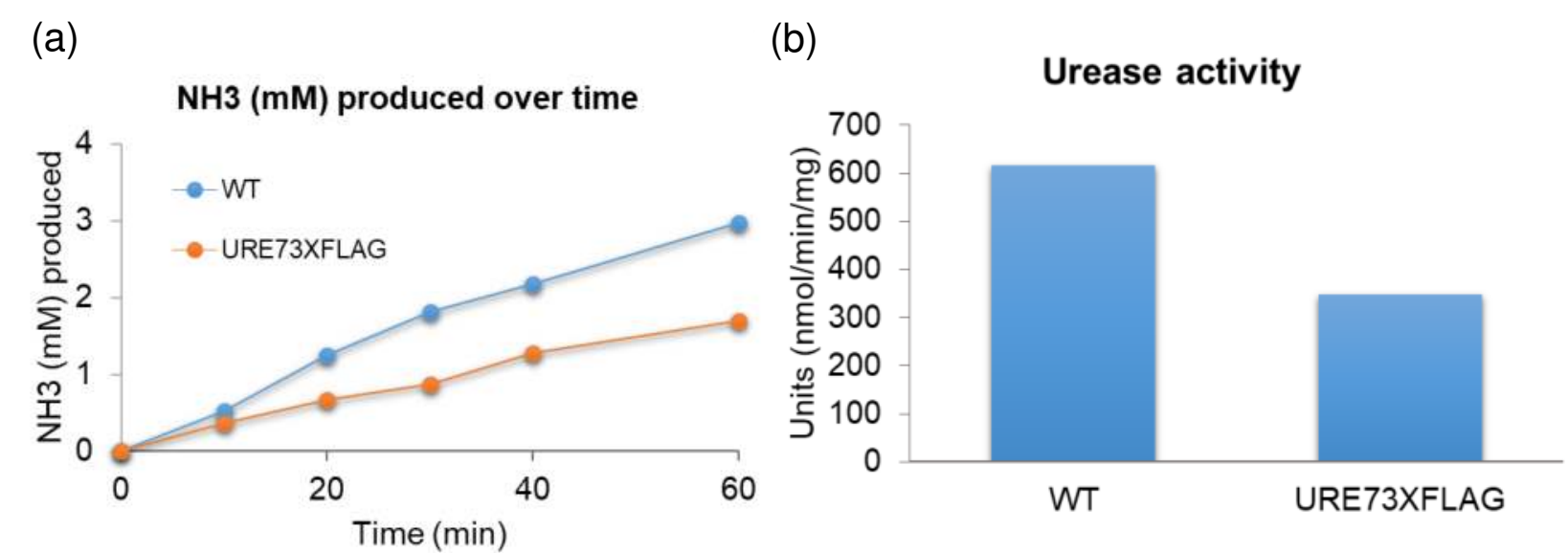

Fig. 3: URE73XFLAG modified cells still possess comparable urease activity as WT cells. (a) $\mathrm{NH}_{3}$ will be release upon urea breakdown that is detected by Nessler's color reagent, (b) One unit will liberate $1 \mu \mathrm{mol} \mathrm{NH}_{3}$ from urea per minute at pH8.2 at $30^{\circ} \mathrm{C}$.

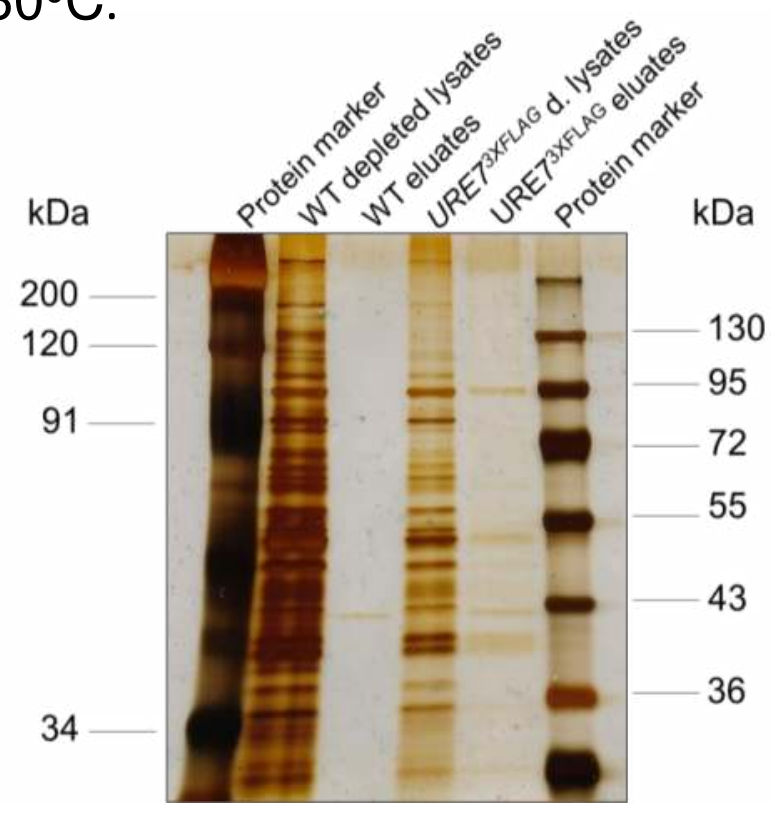

Fig. 4: Co-

immunoprecipitation was carried out using M2 agarose beads (Sigma) and proteins were eluted by competition with 3XFLAG peptide.

Protein electrophoresis through $10 \%$ denaturing polyacrylamide gel.

(a)

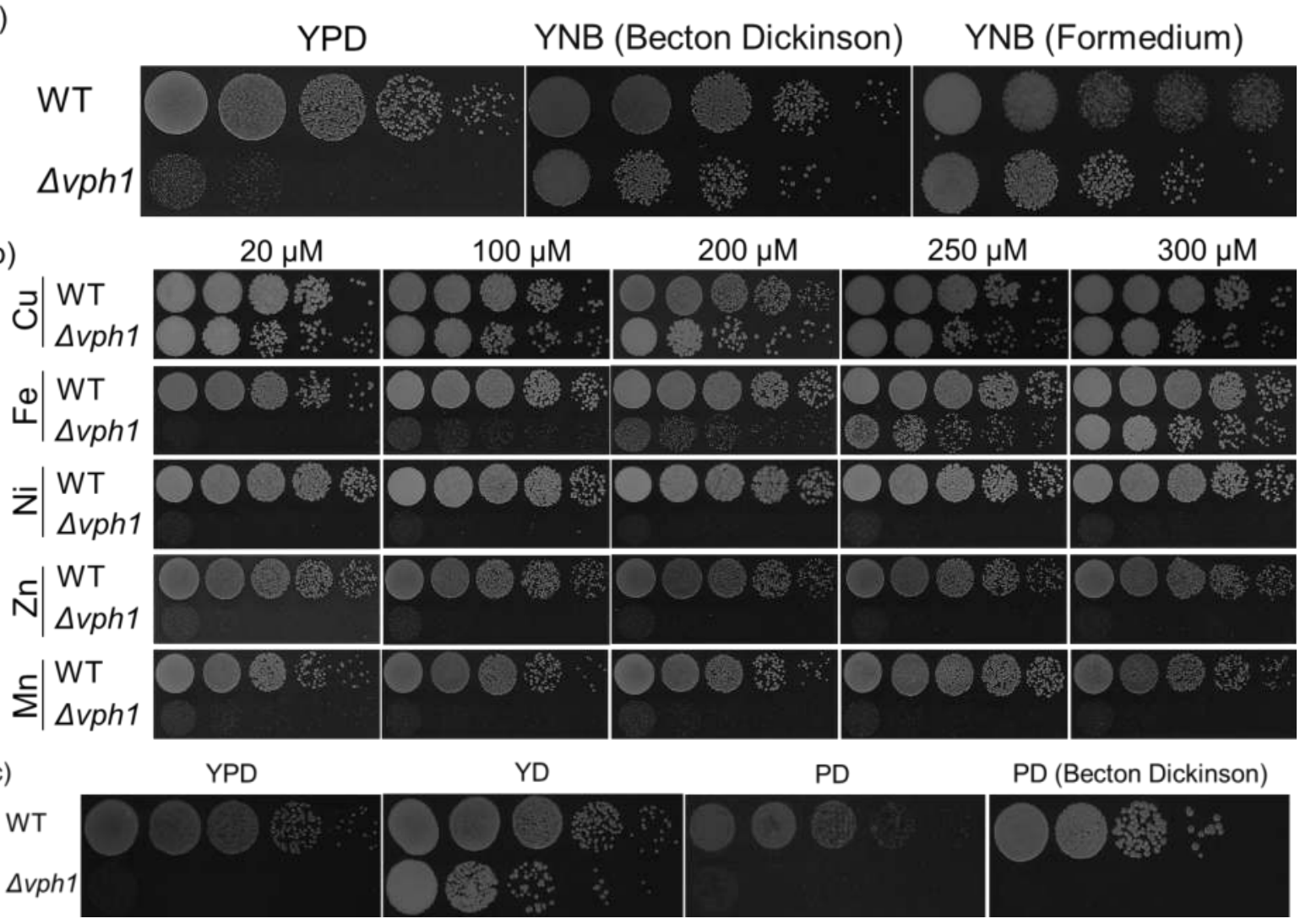

Fig. 5: The growth capability of $\Delta v p h 1$ cells. (a) $\Delta v p h 1$ cells able to grow on CSM medium, (b) on YPD supplemented with $\mathrm{Cu}$ and Fe metals and (c) on YPD with absence of polypeptone.

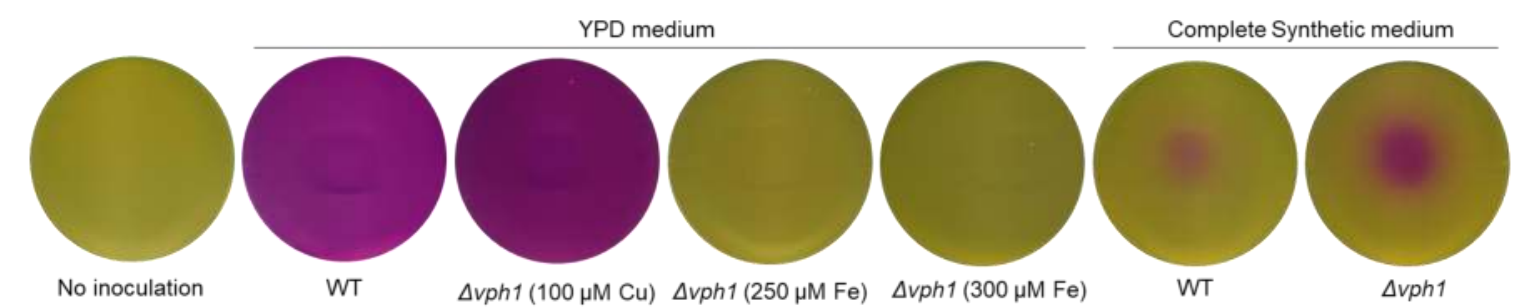

Fig. 6: Copper supplementation in YPD medium promote urease activity.

Conclusion: Tagging one of the urease accessory proteins for purification of urease complex seems to be working well and promise good yield with several optimizations.

Besides that, loss of $\mathrm{VPH} 1$ might have disturb copper machinery that influence cell growth and other phenotype including urease activity. 